\title{
Informed Consent in Social Sciences Research: Ethical Challenges
}

\author{
Carlos Miguel Ferreira ${ }^{1}$, Sandro Serpa ${ }^{2}$ \\ ${ }^{1}$ Polytechnic Institute of Castelo Branco, Estoril Higher Institute for Tourism and Hotel Studies, Interdisciplinary Centre \\ of Social Sciences - CICS.NOVA, Portugal \\ ${ }^{2}$ University of the Azores, Faculty of Social Sciences and Humanities, Department of Sociology, Interdisciplinary \\ Centre of Social Sciences - CICS.UAc/CICS.NOVA.UAc, and Interdisciplinary Centre for Childhood and Adolescence \\ - NICA - UAc, Portugal \\ Correspondence: Sandro Serpa, University of the Azores, Faculty of Social Sciences and Humanities, Department of \\ Sociology, Interdisciplinary Centre of Social Sciences - CICS.UAc/CICS.NOVA.UAc, and Interdisciplinary Centre for \\ Childhood and Adolescence - NICA - UAc, Portugal
}

Received: February 2, 2018

Accepted: March 7, 2018

Available online: March 15, 2018

doi:10.11114/ijsss.v6i5.3106

URL: https://doi.org/10.11114/ijsss.v6i5.3106

\begin{abstract}
Informed consent is a critical procedure for the fulfilment of the ethical dimension in scientific research in social sciences. On the basis of a stance centred in Sociology research practices developed by the authors, this paper reflects on informed consent, its relevance in research, and procedures involved in its production and its concomitant implications. The reflection on the research process is stressed, emphasising the need to not consider the informed consent procedure as something that is fulfilled only once, but rather as something that integrates both the research process and its product and that, therefore, should be continuously considered and assessed throughout research.
\end{abstract}

Keywords: informed consent, ethics in research, sociology, social sciences

\section{Introduction}

This essay seeks to develop a reflection on informed consent as a relevant element in ethical procedures of research in social sciences. To that end, starting from a stance centred in Sociology research practices developed by the authors, the paper discusses what the informed procedure consists of, its relevance in research, the procedures mobilised in its production, and its concomitant implications.

There is a close relationship between scientific knowledge and research. This interdependence is reflected in two dimensions of scientific knowledge: process, procedures involved in the development of a research; product, partial and/or final result of a research and that translates into forms of its dissemination, such as reports, papers and presentations, among several possibilities. These dimensions interconnect in a concomitant way with the respect for epistemological, methodological and ethical rigour and control in the process of production and dissemination of scientific knowledge.

Ethical topos, while not being directly involved in scientific procedures as a technical element for the development and dissemination of successful scientific research, is very relevant in the reflexion on the challenges posed to scientific practice and to the usefulness of science, gaining increasing visibility as a central component to be considered in any research. From our stance, practice consists of collaborative human activities that aim at a certain goal or good that is internal to them, and that require certain standards of excellence to be carried out (MacIntyre, 1984).

The moral imperative of respect for human dignity should be at the heart of any research. This core value is the basis of a number of guiding ethical principles, namely respect for privacy and personal data, respect for vulnerable persons, respect for justice and the principle of integration (this term refers to the principles of non-exclusion and non-discrimination, that is, a research should not be carried out for the benefit of only certain categories of the population) (Sévigny, 2002). In terms of research professional practice, these principles are subject to more specific ethical rules, in particular on free and informed consent, the balance of advantages and drawbacks, the reduction of drawbacks and the optimisation of the advantages of research.

Three cornerstone ethical principles shape research involving human beings: Respect for Persons, Beneficence and Justice (The Belmont Report, 1979). The Principle of Respect for Persons states that participants should be treated as 
«autonomous agents», which entails accepting and being informed about that autonomy, that is, being able to decide autonomously, inasmuch that participants in research are neither passive subjects nor objects; individuals with diminished autonomy should be protected, which has, as consequence, the need to create mechanisms to defend these individuals. The degree of protection should be based on the risk incurred and on the potential benefit. The Principle of Beneficence includes the obligation to do no harm and to seek to maximise benefits and minimise risks. The Principle of Justice requires that no one be denied a benefit which s/he is entitled to or that an unnecessary risk is imposed on him/her, expresses the right to a fair and unbiased treatment and the right to privacy, namely in what regards issues related to anonymity and confidentiality (The Belmont Report, 1979; Ilhéu, 2016; Almeida, 2013).

These ethical principles are translated, at the ethical level, in rules that must be followed by researchers. Some of these main rules are informed consent, risk and benefit assessment, and selection of the research subjects.

\section{The Importance of Ethics in Research}

Scientific research practice is shaped around cognitive standards of theoretical knowledge and technical abilities, as well as ethical standards of values and norms of the respective scientific community (Costa, 1988). This double set of standards shapes the practices and representations of researchers about their activity, scientific writing, and the public image of science.

Ethics and scientific integrity are inherent elements in research activities. Ethics should not be perceived as a constraint, but rather as a dynamic procedure aimed to guide and support the responsible exercise of professional judgment and, thus, enhance the quality of research. Ethics may be defined as a rigorous procedure of reflection on human action, with the purpose of questioning about its meanings, the reasons and values that motivate choices and their foreseeable consequences, so as to guide decisions that respect human dignity. Ethics allows assessing decisions in relation to the values underlying the research project. In his/her professional practice, the researcher should be able to develop this reflection (Bourgeault \& Caron, 2000).

Ethical concerns and dilemmas are, and should be, a concern of any researcher in all kinds of research. In contexts in which regulation occurs, a distinction can be drawn between two ethical dimensions: procedural ethics and ethics in practice (Guillemin \& Gillam, 2004). Procedural ethics refers to one of the first stages of the research process, when the project is submitted to the authorisation of an ethics committee, whether it belongs to the organisations that promote research or to where the work will be developed. This procedural ethics is seen as a sheer formality, a hindrance that has to be overcome in order to progress with the project. It involves the use of a language that the committee understands, free of jargon, but which assures the committee that the researchers are competent, experienced and reliable (Roriz \& Padez, 2017). This situation involves explaining the methodology to be used to a committee that may not be familiar with qualitative methods. On the other hand, ethics in practice regards the ethical issues that emerge in the course of research, the real issues that arise in the fieldwork. These issues are not, normally, addressed in submissions to ethics committees, nor are events that can be anticipated when approval is requested. These situations are «ethically important moments», which, while not being predictable, shape the interpersonal aspects of research and the interactions between the researcher and the participants (Guillemin \& Gillam, 2004; Roriz \& Padez, 2017).

Ethics in research is a core element in the regulation of the scientific practice. It is relevant in the way of proceeding in the respect for the intrinsic and extrinsic values of science, both during the process and in the development and dissemination of the final product(s). Thus, there is no ethically neutral research, and ethics goes through all phases of scientific research, whatever its audience (Gómez, Flores, \& Jiménez, 1999; Tuckman, 2000; Lima, 2006; Graue \& Walsh, 2003; Miller, Werner-Lin, Walser, Biswas, \& Bernhardt, 2017), without forgetting, naturally, the new ethical challenges posed by the Internet and the digital world (Peixoto, 2017; Saunders, Kitzinger, \& Kitzinger, 2015).

The complexity of ethical aspects in a research becomes even more sophisticated given the multiple roles, often in competition, taken on by the researcher him/herself. An illustrative example of this difficulty may be a sociologist who, in conducting a research about/with his/her students, is concurrently taking on the role of researcher and teacher. These two roles may be contradictory in the sense that the development of the research (researcher's stance) may clash with the defence of the class wellbeing (teacher's stance). This is not to mention the inherent power that the teacher has towards individuals that are his/her students, which may be a factor of coercion to participation and to the type of information that will be attained.

There are several findings on the importance ascribed to ethics in research. These findings are related to ethical codes (Gómez et al., 1999; Tuckman, 2000; Bogdan \& Biklen, 1999), such as, in Sociology, the Portuguese Sociological Association (APS, 1992), the Portuguese Association of Professionals in Industry, Organisations and Labour Sociology (APSIOT, 1994), the European Sociological Association (ESA, 2015), and the International Sociological Association (ISA, 2001). Likewise, there is a generalisation of regulations in higher education and research institutions that imply prior assessment of any research project presented either by teachers or researchers, or even by students in training. This 
assessment implies the participation of human beings (but not only), who are part of an ethics committee that is internal to the organisation itself, which will address this ethical dimension (Lima, 2006; Yin, 2009; Ybarra, Kupczynski, Mundy, \& Oller, 2016; Ventura, Mendes, Trevizan, \& Marchi-Alves, 2015; Hardy, 2016), as well as general national laws (Lima, 2006; Farinde, 2014; Ybarra et al., 2016).

This control and assessment of ethics in research can take place through several instances and at different moments: by the researcher, by peers, by an Institutional Review Board (IRB) that is internal to the institution responsible for the research, by governing bodies and by social control itself, before, throughout and after the research. Lima (2006), referring to Lee (1993), puts forward two types of formal structures that regulate research: the proactive (that carry out the assessment prior to the development of the research); and the reactive (that carry out the assessment of the researcher's practices after the research).

Hence, although this is a complex field, the ethical dimension has to be considered in sociological research, and it is possible to present some ethical principles to be considered by the researcher. These principles reflect, to some extent, the main concerns in this field, which are translated into the following rights of the participant respondent: privacy (certain information is kept by the respondent); non-participation (not participate in the research); anonymity (personal non-identification); confidentiality (control over who has access to data); rely on the researcher's sense of responsibility (in the respect for human dignity and not impairing the respondent for having participated in the research, to protect respondents) (Tuckman, 2000, pp. 20-22).

These rights of the subject participating in the research may be materialised, to some extent, also through the application of what is known as informed consent (Saunders et al., 2015; Lima, 2006; Tolich, 2016, among many others). Next section analyses what informed consent is and discusses some aspects involved in its implementation.

\section{Informed Consent}

Informed consent first emerged in the context of the implementation of clinical procedures in the field of Medicine (Cléro, 2016; Farinde, 2014; Sawicki, 2017; Sousa, Araújo, \& Matos, 2015). In this sense, informed consent is underpinned by a "voluntary decision, made by an autonomous and capable person [...] after an informative and deliberative process, aiming at the acceptance of a specific treatment or experimentation, being aware of its nature, its consequences and its risks" (Sousa et al., 2015, p. 9).

The notion of consent reflects the will to complete an agreement and to legitimise acts through this agreement, the absence of which could even be a crime. This first definition translates the ambiguity of a term that is positioned on an axis structured by the opposition between autonomy and constraint (Coste, Costey, \& Tangy, 2008).

Consent is the act by which an individual gives his/her personal adhesion to a decision - that was the initiative of another individual -, which is necessary to the progress towards implementation (Foulquié, 1962). Consent is, at the same time, the adhesion to an external proposition and self-confidence. Deliberation and internal decision are necessary mediations for the voluntary act of consenting (Perdoncin, 2008; Fraisse, 2007). Consent as a relationship (between oneself and the other) is positioned in an indefinite zone, whose features need to be specified. Anchored in an individual conceived as an autonomous and informed person, consent should be «free and informed». Free means an agreement based on the absence of physical constraint (violence, coercion) or psychological constraint (manipulation, deception). Informed refers, in this context, to a reflected and intentional act: informed consent is an act of reason that is different from a passion or a fleeting and contingent desire (Coste et al., 2008).

In medical sciences and clinical practice, informed consent has, over the last years, gained growing acuity, assessing the traditional paternalistic positioning of medicine and opposing the centrality of patient autonomy, in which clinical decisions are progressively shared with the patient and his/her family (Nunes, 2013). Informed consent is, in a sense of negotiation, a communicational, continuous and participated process, through the interaction established between health professionals and individuals, extending in a useful time, defined in each case, by the health situation under consideration (DGS, 2013).

In clinical practice, informed consent has legally defined procedures. In Portugal, the Data Protection Law requires that public and private entities notify the National Data Protection Committee (CNPD) of the treatment of personal data carried out by them. CNPD requires the submission of a clinical research notification form, not only because the data collected are usually not anonymous, but also because the information collected is sensitive and intrusive. European law provides that informed consent is not required for the collection and use of anonymised data (Peixoto, 2016).

In terms of the clinical relationship with the patient, interventions require informed, free and clarified consent. The physician and other health professionals have a duty to inform in accessible language the facts that are relevant for the patient to decide in full knowledge. The structural elements of informed consent may be summarised as follows: competence; communication; understanding; voluntariness; consent (Beauchamp \& Childress, 2012). These structural 
elements, considered sequentially, are a sine qua non condition for consent to be considered valid. The agent provides informed consent if s/he is competent to act, receive complete information, understand that information, decide voluntarily, and finally consent to the intervention. These elements can be subdivided into three fundamental components: preconditions: a) competence (to understand and act); b) voluntariness (in deciding); elements of information: a) communication of information; b) recommendation of a plan; c) understanding; elements of consent: a) decision (in favour of a plan); b) authorisation of the chosen plan (Beauchamp \& Childress, 2012; Nunes, 2013).

The model of regulation of research and protection of subjects involved in biomedical research has been presented as a model for all other forms of research involving human subjects, particularly in social sciences, being also present in the codes of practice of almost all professional organisations, funding agencies and institutions involved in research (Roriz \& Padez, 2017). However, social sciences do not deal with human subjects in clinical experiments. There is no unitary and universal science, but rather scientific backgrounds historically situated, endowed with relative autonomy, own temporality, unequal rhythms of development and unequal insertion into social structures. Emphasis is put on a perspective centred on the theoretical plurality of social sciences, which seek to articulate macro-social dynamics with local processes, allowing the linkage between subjective significances and practices, and that focus on the articulations between systems and actors, between structures and practices, between the reality of social conditions of existence and the social construction of reality (Dubar, 2006; Ferguson, 2016; Morrison, 2017; Sethuraju, Prew, Abdi, \& Pipkins, 2013).

The consent procedure establishes the objective conditions for the development of the research activity and the commitments to ethics, namely the issues inherent in anonymity, the level of intrusion and the degree of sensitivity of the information collected and treated. Several challenges are posed to the different actors in the difficult task of articulating respect for ethical principles, keeping the individuals who are the object of research informed and permanently guaranteeing them the right to free participation, and the urgency to carry out the research, ensuring the epistemological and methodological rigour (Peixoto, 2016).

The informed procedure in the context of scientific research, in many situations, is a "fundamental principle for the ethical acceptability of a study" (Lima, 2006, p. 142). It is important, whenever possible and relevant, to ensure that participants in a research may consciously accept their role, and there must be a guarantee that they have been informed beforehand about the research and its present and future implications, e.g. during the research process and in the product of its dissemination. Thus, this process expresses an explicit agreement to participate in the research, that the participant knows what a reasonable person in the same situation would like to know before consenting to participate, and that such consent is given freely and under no threat whatsoever, or without being unjustifiably induced (Lima, 2006, p. 141).

The fulfilment of these features implies, according to Lima (2006, pp. 142 and 143), that the following elements are present: identification of the researcher, explanation of the objectives and procedures to be used, information on the probable length of the participation, indication of possible risks for participating, information on whether or not compensation for possible damages is available, description of expected benefits resulting from the research, indication of voluntary participation and of the possibility of the respondent's withdrawal at any time, indication of procedures to preserve confidentiality of information, indication of how data will be stored and who will have access to them, indication of people to contact throughout and at the end of the research in case of need, and indication of the entities that promote the research and its context.

The need to obtain this informed consent is even more pressing in situations where participants are minors and/or not fully aware of the implications of their participation, such as children (Miller et al., 2017):

It is critical for investigators and individuals conducting informed consent with families to understand that there are multiple strategies to show respect for children and encourage their active involvement in consent discussions. IRBs should consider educational initiatives, such as training sessions and toolkits, to increase awareness and provide specific guidance regarding communication strategies to increase child participation in informed consent sessions in general, and in decision making about exome sequencing research with disclosure of secondary findings in particular (p. 12).

In the informed consent procedure, the use of a written document signed by both parties is valued, inasmuch that it is evidence of the aware role of the researched/respondent/participant and that of the researcher, with delivery of a copy to the respondent upon signature by both parties (Bogdan \& Biklen, 1999; Lima, 2006). However, these guarantees seldom finish when a standardised document is submitted and signed; they are established as the contact between researchers and participants progresses, before, throughout and after the research (Pegado, Zózimo, \& Lopes, 2016). Some reflections on ethical aspects of research studies have been shifting the view from informed consent as an instrument to informed consent as a process. The respect for the dignity and autonomy of the subject is stressed, which implies ensuring his/her freedom of choice in the decision to participate in the research. This freedom can only become effective 
when the subject has all relevant information, the guarantee of anonymity and confidentiality, the ways of using the information collected and the benefits and risks of participation (Ramos, Junqueira, \& Puplaksis, 2008).

The informed consent procedure guides, also, the management of information that falls outside the scope of scientific research, which happens, for example, in the digital context. The users agree to provide their information, namely in social networks, in a procedure that indicates the conditions under which such information is to be processed and by whom. However, some limitations in the fulfilment of this informed knowledge may arise in this process, such as the user accepting without even reading it, the user not understanding it, be very technical and difficult to understand, or even undergo changes or become outdated over time, among others (Custers, 2016):

Many websites, such as social network sites like Facebook, Twitter and LinkedIn, use quick and easy procedures for providing consent in order to generate Big Data. Consent may be considered outdated when it no longer matches the initial preferences of a user, for instance, because he changed his mind or because the data processing practices have changed significantly (pp. 1-2).

As previously mentioned, informed consent should inform respondents about the implications of their participation in the research. To that end, research projects increasingly need to be assessed by "institutional systems of prior review" (Lima, 2006, p. 138), which can offer greater assurance of compliance with ethical issues and thereby greater confidence for participants, peers, the organisation, supervisory and governing entities and the general public. However, this assessment may also prevent the focus on certain topics considered more sensitive (Lima, 2006):

Rather than adopting a combative approach to ethics review boards - cast as another angry and frustrated social scientist - I systematically question the relationship between social scientists and ethics review boards. Further research is required to examine how social scientists reflexively relate to ethics in practice in their research and in the research conducted by their students with special attention focused on data collected prior to commencing postgraduate studies. These twenty five respondents expose an ethical disjuncture within the academy. Ethical considerations examined in ethical review seem more stringent at the start of the research process than at the end of the academic pedagogy (Tolich, 2016, p. 26).

Another difficulty has to do with the individuals' ability to clearly and mindfully understand what is involved in informed consent, as well as in the quality and quantity of information to provide in order to fulfil the purposes of informed consent, but without affecting subsequent research that justifies informed consent and cultural diversity themselves (Farinde, 2014; Lima, 2006).

Another factor that brings high complexity to the successful application of informed consent is that it corresponds to the research to be carried out - from the intentions to what will actually be practised during the research process, as well as its dissemination. This entails the need to have a very clear idea, at least as precise as possible, of the research that will be developed, as well as the type of final products. Thus, the moment when the starting and exploration question is defined is critical. As stated by Lima (2006), research objectives and strategies must be clearly defined in order to fulfil the purposes of informed consent.

Uncertainty may be present in any research, and there is always some room for reformulations (Quivy \& Campenhoudt, 1992). However, these reconfigurations are more recurring in discovery- or qualitative-type research than in evidenceor quantitative-type research (Bogdan \& Bicklen, 1999; Yin, 2009; Gómez et al., 1999). Unpredictability is strengthened in the study of contemporary situations: "a contemporary phenomenon in its real-life context" (Yin, 2009, p. 73).

\section{Informed Consent in Social Sciences: Ethical Challenges}

In research procedures in the social sciences field, specifically in Sociology, informed consent emerged later, despite the existence of some affinities with informed consent used in medical research (Yin, 2009). Currently, the existence of informed consent is becoming, whenever possible, more widespread (Peixoto, 2017). ISA's Code of Ethics itself is explicit when it states: "The consent of research subjects and informants should be obtained in advance" (ISA, 2001, para. 21). Ethics committees themselves tend to require informed consent in most proposals of research projects (e.g. Lima, 2006).

Social scientists' research and other professional activities should be based on prior and free informed consent of individuals who are expected to participate in research, education or intervention processes. It is not permissible, except in very specific situations foreseen or to be foreseen in the codes of ethics of professional associations, to use human beings as participants in any research without prior and free informed consent on their part or on the part of their legal representatives. This consent must always be obtained before the information is collected through any form of communication, interaction or intervention with the participants, or when it is about observing behaviours in a private environment or in social contexts in which the participant can legitimately expect that no observation takes place 
(Almeida, 2013). Management of anonymity, confidentiality and level of sensitivity of the information collected and treated poses relevant ethical and deontological issues also to social scientists in their professional activity.

Informed consent contains three components: information, comprehension and voluntariness (The Belmont Report, 1979). Informed consent entails that participants should receive detailed information on the research they are participating in, so that they can make a voluntary, informed and rational decision regarding whether or not to participate in such research.

It is important to formulate very carefully the research contract between researchers and participants, inherent in the granting and development of a research project within the scope of social sciences. In research processes, the issue of status differences between researchers and individuals, groups and organisations involved in the research is often raised (Lie \& Witteveen, 2017). These differences in status should not be manipulated by researchers to obtain coercive information, nor should social scientists allow themselves to be manipulated by informants (Almeida, 2013). In the processes of obtaining informed consent, social scientists should explain as much as possible to the participants their professional identity, as well as the research topic, who is funding and developing it, the nature, objectives, procedures and institutional framework of the work they carry out. They should also explain the individual and social risks and benefits of participation, clarifying exactly what is intended with the research and avoiding false expectations, so many times multiplied by the urgency with which such procedures tend to be carried out (Veloso, Freire, Oliveira, \& Lopes, 2012).

Thus, participants should be informed about the nature and objectives of the research, specifying certain elements: the expected duration; the procedures and their level of intrusion; the right to not participate or to withdraw at any time; the potential risks, negative effects or any inconvenience; the benefits of the research for a given community; the incentives for the participation in the research, whether cash payments or other kind of rewards; who are the individuals and which contacts allow obtaining additional information about the research (Peixoto, 2016). Participants should also be informed about the purpose of data collection and treatment, and it should be stated whether these data are used for strictly scientific purposes; moreover, participants are also entitled to know who will collect and treat the data. In the case of personal data, they should be told whom the data will be communicated to, under what conditions they can access and rectify them, and what the indispensable and optional data are (Peixoto, 2016). Hence, researchers must have enough emotional maturity and moral integrity to manage the situation of sociological ambivalence that confronts them with the «dilemma of double fidelity»: to the scientific community that seeks results and to the collective, or social groups, that have entrusted them with the information (Carmo \& Ferreira, 1998).

This information should, whenever possible (Lie \& Witteveen, 2017), be written in a language that is easily understood by the selected participant population and read by the participants. Participants are then invited to sign and date a document stating that they agree to participate. Informed consent should always include a clause according to which participants are free to withdraw from the study at any time (CIS, 2017; Peixoto, 2017).

In several research studies, consent formalisation is materialised by the indication in the heading of the questionnaires or by an oral explanation (whenever possible, it should be recorded) that is conveyed to the participants regarding the scope of the research, its objectives and who carries it out. The type of recipient conditions consent formalisation; it is important to know whether participants in the research understood their rights and whether they have objective and legal conditions to participate in the research. Since information for consent is often provided orally, acceptance may involve a written consent. The form should contain a detailed explanation of the type of information to be collected, how it will be used and by whom. The form should be signed by the researcher responsible for the research protocol and the individual who gives consent (Peixoto, 2016).

Several consent forms are structured in two parts: one encompasses information on the research project, and the other refers to the participant or his/her legal representative's statement in the research. Information to the participants includes the research title, the researchers' name and functions, scope and description of the research project, research objectives, location where the research will be developed, methodological strategy to be used (choice of methods and techniques, procedures for data collection and recording, tasks required of participants, interventions to be carried out, duration of the participation, frequency of data collection, instructions, questionnaires, interview scripts, and tests, among others, may be provided in annex), advantages and benefits, drawbacks and risks, project duration, confidentiality of the data collected, results dissemination, researchers' responsibilities, participation and withdrawal, compensation (incentives offered to participants for their participation), project funders and managers, conflicts of interest (someone involved in the design and development of the research has private interests that may be related to the elements analysed in the study), and questions on the research. Participants should have the opportunity to ask questions and clarify any doubts they may have, either initially or at any time in the course of the research, or even after it is concluded (Lima, 2006; Peixoto, 2016, 2017). 
The researcher may mobilise the post-experimental debriefing to explain the participants in more detail why s/he chose the questions asked, or why s/he asked them to perform the tasks they did. If any mistake has been found in the study, this should be disclosed at this point. In addition, if any of the questions or topics that have been raised can cause stress to participants (including any misunderstandings), the participants' level of stress should be assessed and some response should be given as far as possible; if problems persist, additional steps should be taken (e.g. channelling to a support environment). Debriefings may be made in writing; however, they are considered to be more effective if they are verbally delivered to participants directly after the study (CIS, 2017).

Another ethical challenge concerns privacy and confidentiality. The social scientist, in the exercise of his/her professional activity, even in the absence of adequate legal provisions, should focus on the principles of privacy and confidentiality, ensuring the protection of confidential information s/he has access to in the course of the research, teaching or professional practice. Secrecy information remains confidential even after the death of those who have provided it. The duty of confidentiality extends to the members of the research teams and to all those who have access to the research process throughout its course.

The right to privacy corresponds to the participant's right to define when and under what conditions his/her behaviours, attitudes or beliefs may be made public (Crête, 2003). The right to privacy encompasses anonymity, meaning that the researcher or any other person cannot associate a participant with the information, and confidentiality, which corresponds to a guarantee that all information provided by the participants will not be publicly disclosed or made accessible to persons other than those involved in the research, unless explicit authorisation is given to do so (Ilhéu, 2016, pp. 18-19). Thus, the level of intrusion cannot question the individuals' right to their privacy and all information obtained in a confidential context should be maintained as such. Even if the researcher has obtained the consent to use the real name of people or organisations, if this is not the fundamental aspect to characterise the object or phenomenon addressed, s/he must anonymise, whenever possible, the information collected. Social scientists should try to prevent the collection, use and dissemination of information from being detrimental to those who provide it or to those about whom the information is provided. When confronted with confidential information that could endanger the life or health of researchers, participants or other individuals, social scientists should weigh the advantages and disadvantages of maintaining the confidentiality of the information. In such cases, researchers may, whenever possible, consult the ethical boards of professional associations (Almeida, 2013).

Confidentiality is also based on the precautionary principle, which warns of the vicissitude of the changes that social realities are subject to. Very detailed and non-anonymised information that is harmless in one context may become inopportune in another context (Peixoto, 2016).

Furthermore, confidentiality requires increased care in the storage of confidential data (Mukungu, 2017). Whenever researchers collect confidential information, they should take into account the use of such information in the long term, namely its subsequent inclusion in public archives or its analysis by other social scientists, and should provide for ways of preserving confidentiality under such circumstances. Researchers have a strict obligation to ensure the protection of information archives or databases that are subject to confidentiality or anonymity. Only in case of absolute and duly justified need can these archives or databases be transferred to other professionals from diverse social sciences, provided that they are bound to a code of ethics (Almeida, 2013).

Another ethical challenge linked to the previous ones refers to the professional work of social scientists with vulnerable populations, understood as particularly exposed to the risk of damage (Walsh, 2009). These poorly educated populations, unfamiliar with research procedures, do not share the researcher's ethos, which raises some issues. There is the need to overcome a formal and bureaucratic logic of the consent, which runs the risk of becoming an instrument of exclusive protection of researchers, contained in the metaphor «blank cheque», rather than guaranteeing the preservation of the rights of populations and individuals that are the object of research (Pegado et al., 2016). When working with populations with low levels of literacy, researchers also face the challenge of translating the scientific and technical language often used in some informed consent models required by ethics committees into a language that respondents understand. There is also the issue of the risk of intimidation of the participants in the research, who, faced with the obligation to sign a formal document that is culturally strange to them, may fear the loss of anonymity - which, paradoxically, this document guarantees them - and raise suspicions about its use (Pegado et al., 2016).

For these populations, as well as for those participating in research studies with the collection of information that identifies individuals as having participated in the study (e.g. undocumented immigrants or studies on undesirable or illegal behaviour), oral consent should be obtained. Any study requiring oral consent should be reviewed by an ethics committee before being carried out. In addition, there are some studies (e.g. those strictly observational) (Plankey-Videla, 2012) for which obtaining informed consent is difficult (especially prior to the study). In the case of research studies involving only observation of public behaviour without the collection of any identifying information, 
the study may be exempted from informed consent (which is considered to be tacitly given by performing the behaviours in public). However, if any intervention occurs in the situation or if identification information is collected, participants should have the opportunity, later on, to refuse the use of their data in the research. Research studies involving the intervention or identification information collected in public places should be reviewed by the ethics committee prior to their implementation. When participants are selected in organisations, formal consent of the organisation should be obtained (CIS, 2017).

In the case of research involving other cultures, illegal activities, sensitive political situations and others, it may be difficult, impossible or culturally inappropriate to obtain informed consent, and, thus, authorisation for its exemption should be sought. The signing of informed consent documents may, under some circumstances, violate anonymity and create or increase risks for participants or researchers. Consequently, there may be situations where informed consent may be waived by a competent authority or by the ethics committees of professional associations. These situations are not detrimental to the participants, due to the lack of an alternative in which informed consent may be obtained, given the importance of the research (Almeida, 2013).

Voluntary participation of potential participants is vital, but it often takes place through subtle motivation processes (by using benefits, the prestige of the participant, the sponsors or the researcher, awards...) and is based on undetailed information and, hence, informed consent is not always fully achieved (Ilhéu, 2016). If there is some reward for participating (e.g. some payment), at least a partial reward should be given to the participants, even if they do not complete the entire study. In a multi-session research study, a participant who is only present in one session should be compensated for having been present in that session (CIS, 2017).

Any research involving interaction between the observer and the observed comprises risks. However, there are procedures that are likely to generate risks, understood here as a possibility of undesirable consequences for the individuals participating in the research (Pegado et al., 2016). The general degree of risk allows classifying research into four types: «no foreseen risk», which is common to most social sciences research studies and to some medical sciences; «minimum temporary risk», when it does not exceed the risks normally found in everyday life, and which occurs only during the course of the research (complete questionnaires, be interviewed); «unusual levels of temporary risk», when they go beyond daily life and extend beyond the research; «unavoidable permanent damage» during and/or after the research. In this degree of risk, research should not be carried out if the damage is foreseeable before its start (Ilhéu, 2016).

In research practice, it is necessary to place a special focus on collateral damage, whether it consists of physical, psychological, legal, financial or any other type of damage. This is the case of research studies that promote manipulation, dissimulation or coercion on participants. It is important to avoid causing damage to the participants in a research, to those who are directly or indirectly involved in the professional practice of social scientists and also to the scientist that develops his/her professional activity. To prevent this situation, the observation protocols have to be thought, weighted and tested properly and beforehand.

Another ethical challenge inherent in one of the most complex aspects of the administration of research methodologies and techniques is deliberate or strategic deceit. Deceit is one of the grey zones in the use of certain methodologies, especially in the most intrusive ones, notwithstanding the prevalence of the basic principle that lie and deliberate deceit in research should always be avoided (Peixoto, 2016, 2017). It may be argued that observing others without explaining the role of the observer is to deceive, is to hoax. Other arguments maintain that there is deceit only when data are manipulated to obtain desired results. Debates around this issue highlight several examples that show the need to methodologically resort to deceit. Those that advocate the use of deceit argue that the negative impacts on respondents are minimal. This discussion refers to the dilemmas associated with participant research, inasmuch that the prior identification of the social scientist as such removes agents from the «natural» universe that is sought to be «naturally» observed (Peixoto, 2016).

When, in the absence of a better alternative, research based on hoaxing is used, the researcher should inform the participants, after concluding the research, as a way to mitigate possible damage, through a process of dehoaxing and desensitisation. In the process of dehoaxing, the researcher uses interviews to explain the reasons for dissimulation, to convince participants that dissimulation was useful and that it will cause no harm in the future. In the process of desensitisation - through which the researcher, upon conclusion of the research, helps participants to know themselves on the basis of information obtained as a result of having participated in the research - it is intended to explain to participants that their new behaviours are different, but do not fall outside the behavioural patterns and, hence, are normal and their origin is in the circumstances in which the research was carried out. It is sought, through rationalisation, that the participant accepts a behaviour that could conflict with his/her self-perception of what is right or wrong (Ilhéu, 2016, p. 14). 


\section{Conclusion}

Despite being a very important procedure in the fulfilment of the ethical dimension in scientific research, informed consent per se does not automatically ensure compliance with the ethical dimension. It is critical that all researchers be aware that, in any situation and even with informed consent, it is important, throughout sociological and other social sciences' research, as well as in its dissemination, to fulfil the promises made (Carrasco \& Hernández, 2000). As a process (Farinde, 2014; Plankey-Videla, 2012), informed consent is not established once and for all after the initial formal agreement, but it often needs to be renegotiated, as alerted by Lima (2006).

Informed consent should be expressly given by the participant or by whosoever legally represents him/her. European law provides that informed consent is not required for the collection and use of anonymised data. In Portugal, the Data Protection Law requires that public and private entities notify CNPD of all treatment of personal data that they carry out. Therefore, the central issues are related to anonymity, the level of intrusion and the degree of sensitivity of the information collected and treated. So, as far as possible, social scientists should collect and treat data anonymously. Yet, anonymous data treatment is not enough. It is important to ensure the principle that if anonymous data are not strictly necessary for the research, then such data should not be collected (Peixoto, 2016).

Ultimately, and "Whatever the ethical framework used by the researcher, it is important that s/he honours his/her commitments" (Lima, 2006, p. 136), in respect for the rights of participants who depend, in the end, on the researcher's conscious responsibility (Carmo \& Ferreira, 1999; Lima, 2006; Bogdan \& Bicklen, 1999).

\section{Acknowledgments}

University of the Azores, Interdisciplinary Centre of Social Sciences - CICS.UAc/CICS.NOVA.UAc, UID/SOC/04647/2013, with the financial support of FCT/MEC through national funds and when applicable co-financed by FEDER under the PT2020 Partnership Agreement.

\section{References}

Almeida, J. F. D. (2013). Ética da investigação em ciências sociais. [Research ethics in social sciences]. Sociologia On Line, 6. revista.aps.pt/wp-content/uploads/2017/09/N6_art-4_Jorge-Almeida.pdf

Associação Portuguesa de Profissionais em Sociologia Industrial, das Organizações e do Trabalho (APSIOT) (1994). Código deontológico [Code of ethics]. http://www.apsiot.pt/index.php/apresentacao/codigo-deontologico.

Associação Portuguesa de Sociologia (APS) (1992). Código deontológico [Code of ethics]. Lisboa: APS.

Beauchamp, T. L., \& Childress, J. F. (2012). Principles of biomedical ethics, $7^{\text {th }}$ edition. New York: Oxford University Press.

Bogdan, R., \& Biklen, S. (1999). Investigação qualitativa em educação: Uma introdução à teoria e aos métodos. [Qualitative research in education: An introduction to theory and methods]. Porto: Porto Editora.

Bourgeault, G., \& Caron, L. (2000). Éthique: Méthodes et interventions - de quoi parle-t-on? [Ethics: Methods and interventions - What are we talking about?] In A. Lacroix \& A. Létourneau (Dirs.), Méthodes et Intervention en Éthique Appliquée [Methods and Intervention in Applied Ethics]. St-Laurent: Éditions Fides.

Carmo, H., \& Ferreira, M. M. (1998). Metodologia da investigação. [Research methodology]. Lisboa: Universidade Aberta.

Carrasco, J. B., \& Hernández, J. F. C. (2000). Aprendo a investigar en educación. [I learn to investigate in education]. Madrid: Ediciones RIALP.

Centro de Investigação e Intervenção Social (CIS). (2017). Consentimento informado e debriefing [Informed consent and debriefing]. Lisboa: ISCTE-IUL.

Cléro, J. P. (2016). Informed consent. Postmodern Openings, 7(2), 15-23. https://doi.org/10.18662/po/2016.0702.02.

Costa, A. F. D. (1988). Cultura profissional dos sociólogos. [Professional culture of sociologists]. Sociologia - Problemas e Práticas, 5, 107-124.

Coste, F., Costey, P., \& Tangy, L. (2008). Consentir: Domination, consentement et déni [Consent: Domination, consent and denial]. Tracés. Revue de Sciences Humaines, 14, 5-27. https://doi.org/10.4000/traces.365

Crête, J. (2003). A ética em investigação social [Ethics in social research]. In B. Gauthier (Ed.), Da problemática à colheita de dados [From the problem to data collection] (pp. 233-254). Loures: Lusociência.

Custers, B. (2016). Click here to consent forever: Expiry dates for informed consent. Big Data \& Society, 3(1), 1-6. https://doi.org/10.1177/2053951715624935.

Direção-Geral da Saúde (DGS). (2013). Consentimento informado, esclarecido e livre para atos terapêuticos ou 
diagnósticos e para a participação em estudos de investigação [Informed, clarified and free consent to therapeutic acts or diagnoses and for participation in research studies]. Rule No. 015/2013 of October 3, 2013.

Dubar, C. (2006). Le pluralisme en sociologie: Fondements, limites, enjeux [Pluralism in sociology: Foundations, limits, issues]. Socio-logos, 1. http://journals.openedition.org/socio-logos/pdf/20.

European Sociological Association (ESA) (2015). Statement of the ethical guidelines of the European Sociological Association. https://www.europeansociology.org/about-esa/governance/ethical-guidelines.

Farinde, A. (2014). The history and current status of informed consent. International Journal of Social Work, 1(1), 78-92. https://doi.org/10.5296/ijsw.v1i1.5778.

Ferguson, S. J. (2016). The center does hold: The sociological literacy framework. Teaching Sociology, 44(3), 163-176. https://doi.org/10.1177/0092055x16651478.

Foulquié, P. (1962). Dictionnaire de la langue philosophique [Dictionary of the philosophical language]. Paris: PUF.

Fraisse, G. (2007). Du consentement [Consent]. Paris: Seuil.

Gómez, G. R., Flores, J. G., \& Jiménez, E. G. (1999). Metodología de la investigación cualitativa [Qualitative research methodology]. Málaga: Ediciones Aljibe.

Graue, M. E., \& Walsh, D. J. (2003). Investigação etnográfica com crianças: Teorias, métodos e ética. [Ethnographic research with children: theories, methods and ethics]. Lisboa: Fundação Calouste Gulbenkian.

Guillemin, M., \& Gillam, L. (2004). Ethics, reflexivity, and 'ethically important moments' in research. Qualitative Inquiry, 10(2), 261-280. https://doi.org/10.1177/1077800403262360.

Hardy, M. C. (2016). Drafting an effective ethical code of conduct for professional societies: A practical guide. Administrative Sciences, 6(4), 16, 1-11. https://doi.org/10.3390/admsci6040016

Ilhéu, J. R. (2016). Ética na investigação social. Uma proposta de ensino. [Ethics in social research. A teaching proposal]. Desenvolvimento e Sociedade, 1, 7-29.

International Sociological Association (ISA) (2001). Code of ethics. http://www.isa-sociology.org/en/about-isa/code-of-ethics/

Lie, R., \& Witteveen, L. (2017). Visual informed consent: Informed consent without forms. International Journal of Social Research Methodology, 20(1), 63-75. https://doi.org/10.1080/13645579.2015.1116835.

Lima, J. Á. de (2006). Ética na investigação. [Ethics in research]. In J. Á. de Lima, \& J. A. Pacheco (Eds.), Fazer investigação [Do research] (pp. 127-159). Porto: Porto Editora.

MacIntyre, A. (1984). After virtue. A study in moral theory ( $2^{\text {nd }}$ Ed.). Notre Dame: University of Notre Dame Press.

Miller, V. A., Werner-Lin, A., Walser, S. A., Biswas, S., \& Bernhardt, B. A. (2017). An observational study of children's involvement in informed consent for exome sequencing research. Journal of Empirical Research on Human Research Ethics, 12(1), 6-13. https://doi.org/10.1177/1556264616674096

Morrison, A. (2017). A sociologist teaches history: Some epistemological and pedagogical reflections. Educational Studies, 53(3), 233-246. https://doi.org/10.1080/00131946.2017.1297301

Mukungu, K. (2017). 'How can you write about a person who does not exist?': Rethinking pseudonymity and informed consent in life history research. Social Sciences, 6(3), 86, 1-9. https://doi.org/10.3390/socsci6030086

Nunes, R. (2013). Consentimento informado [Informed consent]. Anais da Academia, 3, 1-28. https://www.google.pt/url?sa=t\&rct=j\&q=\&esrc=s\&source=web\&cd=1\&ved=0ahUKEwjXtOfA76rZAhXGzxQK HSsrAicQFggoMAA\&url=http\%3A\%2F\%2Fwww.academianacionalmedicina.pt\%2FBackoffice\%2FUserFiles\%2 FFile\%2FDocumentos\%2FConsentimento\%2520Informado-RuiNunes.pdf\&usg=AOvVaw3J5UgYQyS8gDb9J2I ot-6d.

Pegado, E., Zózimo, J., \& Lopes, N. (2016). Histórias de (uma) vida: Desafios e dilemas éticos na investigação com idosos [Life stories: Challenges and ethical dilemmas in research with the elderly]. Sociologia On Line, 12, 5-21. https://doi.org/10.30553/SOCIOLOGIAONLINE.2016.12.1

Peixoto, P. (2016). Ética e questões deontológicas na sociologia e na sociedade do consentimento [Ethics and deontological issues in sociology and in society of consent]. http://www4.fe.uc.pt/fontes/etica_deontologia_ sociologia.html.

Peixoto, P. (2017). Ética e regulação da pesquisa nas ciências sociais na sociedade do consentimento [Ethics and regulation of research in social sciences in the society of consent]. Educação, 40(2), 160-169. https://doi.org/10.15448/1981-2582.2017.2.27005 
Perdoncin, A. (2008). Consentement des femmes et politique. Note sur Du consentement de Geneviève Fraisse [Consent of women and politics. Note on the consent of Geneviève Fraisse]. Tracés, 14. https://doi.org/10.4000/traces.400.

Plankey-Videla, N. (2012). Informed consent as process: Problematizing informed consent in organizational ethnographies. Qualitative Sociology, 35(1), 1-21. https://doi.org/10.1007/s11133-011-9212-2

Quivy, R., \& Campenhoudt. L. V. (1992). Manual de investigação em ciências sociais [Handbook of research in social sciences]. Lisboa: Gradiva.

Ramos, D. L. de P., Junqueira, C. R., \& Puplaksis, N. de V. (2008). Benefícios da avaliação ética de protocolos de pesquisas qualitativas [Benefits of ethical evaluation of qualitative research protocols]. In I. C. Z. Guerriero, M. L. S. Schmidt, \& F. Zicker (Eds.), Ética nas pesquisas em ciências humanas e sociais na saúde [Ethics in human and social sciences research in health] (pp. 193-205). São Paulo: Aderaldo \& Rothschild Editores.

Roriz, M., \& Padez, C. (2017). A regulação ética da investigação e os desafios postos às práticas etnográficas [Ethical regulation of research and the challenges of ethnographic practices]. Etnográfica, 21(1), 75-95. https://doi.org/10.4000/etnografica.4820

Saunders, B., Kitzinger, J., \& Kitzinger, C. (2015). Participant anonymity in the internet age: From theory to practice. Qualitative Research in Psychology, 12(2), 125-137. https://doi.org/10.1080/14780887.2014.948697

Sawicki, N. N. (2017). Informed consent as societal stewardship. The Journal of Law, Medicine \& Ethics, 45(1), 41-50. https://doi.org/10.1177/1073110517703098

Sethuraju, N. (R.), Prew, P., Abdi, A., \& Pipkins, M. (2013). The consequences of teaching critical sociology on course evaluations. Sage Open 3(3), 1-15. https://doi.org/10.1177/2158244013496182

Sévigny, B. (Coord.) (2002). Éthique de la recherche sociale. Consentement libre et éclairé. Confidentialité et vie privée [Ethics of social research. Free and informed consent. Confidentiality and private life]. Québec: Fonds de Recherche sur la Société et la Culture.

Sousa, J., Araújo, M., \& Matos, J. (2015). Consentimento informado. Panorama atual em Portugal. [Informed consent. Current panorama in Portugal]. Revista Portuguesa de Ortopedia e Traumatologia, 23(1), 6-17.

The Belmont Report - Ethical principles and guidelines for the protection of human subjects in research (1979). The National Commission for the Protection of Human Subjects of Biomedical and Behavioral Research. https://www.hhs.gov/ohrp/sites/default/files/the-belmont-report-508c_FINAL.pdf

Tolich, M. (2016). A worrying trend. Ethical considerations of using data collected without informed consent. Fronteiras: Journal of Social, Technological and Environmental Science, 5(2), 14-28. https://doi.org/10.21664/2238-8869.2016v5i2.p14-28

Tuckman, B. W. (2000). Manual de investigação em educação [Handbook of research in education]. Lisboa: Fundação Calouste Gulbenkian.

Veloso, L., Freire, J., Oliveira, L., \& Lopes, N. (2012). Questões deontológicas e de metodologia de investigação em sociologia. $\mathrm{O}$ caso do interesse público e das profissões [Deontological issues and methodology of research in sociology. The case of public interest and professions]. Sociologia, Problemas e Práticas, 69, 87-98. https://doi.org/10.7458/spp201269788

Ventura, C. A. A., Mendes, I. A. C., Trevizan, M. A., \& Marchi-Alves, L. M. (2015). Research involving human subjects and the role of institutional review boards in Brazil. International Journal of Social Science Studies, 3(3), 1-7. https://doi.org/10.11114/ijsss.v3i3.717

Walsh, S. A. (2009). Conducting research with the elderly: Ethical concerns for a vulnerable population. Southern Online Journal of Nursing Research, 9(4). http://www.resourcenter.net/images/snrs/files/sojnr_articles2/Vol09Num04 Art03.pdf

Ybarra, A., Kupczynski, L., Mundy, M. A., \& Oller, S. D. (2016). Analysis of faculty knowledge of human subjects protections in research. Journal of Studies in Education, 6(4), 20-32. https://doi.org/10.5296/jse.v6i4.10023

Yin, R. K. (2009). Case study research. Design and methods. Los Angeles: SAGE.

\section{Copyrights}

Copyright for this article is retained by the author(s), with first publication rights granted to the journal.

This is an open-access article distributed under the terms and conditions of the Creative Commons Attribution license which permits unrestricted use, distribution, and reproduction in any medium, provided the original work is properly cited. 